See Article page 2107.

\section{Commentary: Rome wasn’t built in a day: Learning from initial cohort studies for patients with coronavirus disease receiving extracorporeal membrane oxygenation}

\author{
HelenMari Merritt-Genore, DO, ${ }^{\mathrm{a}}$ and \\ Ryan Zavala, $\mathrm{CCP}^{\mathrm{b}}$
}

With pandemic data flowing like a fire hydrant spray, it is hard to determine when to take a drink. This retrospective cohort study ${ }^{1}$ includes hundreds of patients with coronavirus disease 2019 (COVID-19) from across the United States supported with extracorporeal membrane oxygenation (ECMO). Although one may critique a lack of standardized initiation and management criteria, it is important to consider where we all were during this time period. Taking that perspective into account, it is easier to take a sip and find yourself refreshed by the authors' efforts to collaborate and collect data during the initial pandemic phases.

In this cohort of nearly 300 patients, more than half of patients survived their hospitalization and approximately $40 \%$ of surviving patients were discharged directly to home-both encouraging statistics compared with the first reports from international studies with small cohorts and poor outcomes. ${ }^{2}$ Specific predictors of outcomes in this cohort were renal function, age, elevated lactate dehydrogenase, and cardiopulmonary resuscitation. When to cannulate was also a predictor of outcomes because those with earlier ECMO initiation were more likely to survive. It is known that renal dysfunction and the need for renal

\footnotetext{
From the a Department of Cardiothoracic Surgery, Heart Consultants, Methodist Physicians' Clinic, Omaha, Neb; and ' Division of Perfusion, Nebraska Methodist Hospital, Omaha, Neb

Disclosures: The authors reported no conflicts of interest.

The Journal policy requires editors and reviewers to disclose conflicts of interest and to decline handling or reviewing manuscripts for which they may have a conflict of interest. The editors and reviewers of this article have no conflicts of interest.

Received for publication May 26, 2021; revisions received May 26, 2021; accepted for publication May 26, 2021; available ahead of print June 1, 2021.

Address for reprints: HelenMari Merritt-Genore, DO, Department of Cardiothoracic Surgery, Heart Consultants, Methodist Physicians' Clinic, 120 N 103rd Plz, Omaha, NE 68114 (E-mail: helenmari.merritt@gmail.com).

J Thorac Cardiovasc Surg 2022;163:2117-8

$0022-5223 / \$ 36.00$

Copyright (c) 2021 by The American Association for Thoracic Surgery

https://doi.org/10.1016/j.jtcvs.2021.05.040
}

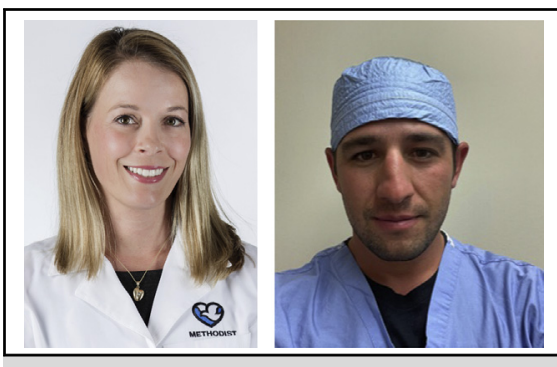

HelenMari Merritt-Genore, DO, and Ryan Zavala, CCP

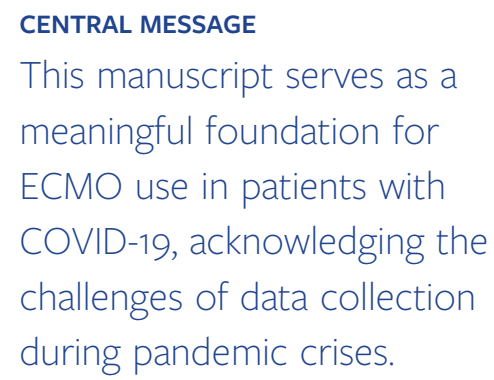

replacement therapy portends a poorer outcome, with up to an $81 \%$ increase in mortality in patients receiving ECMO. ${ }^{3}$ Elevated creatinine levels increased mortality; however, data were missing for utilization of renal replacement therapy, and thus its influence on survival in this population is difficult to interpret. Although $12 \%$ of the population received cardiopulmonary resuscitation during their admission, it was not necessarily immediately proximate to their cannulation; therefore, not technically extracorporeal cardiopulmonary resuscitation.

Approximately 1000 ECMO centers worldwide and 300 US centers exist. These data come from 19 centers clustered geographically in eastern and midwestern US cities, and may not represent all experiences. Additionally, the population included predominately Hispanic patients with a narrow range for age (39-57 years) and body mass index (29-37), with relatively normal kidney function and low precannulation lactate levels. This suggests a selection pressure was applied: sicker and older patients may have been excluded due to sparse resources. Selection pressure may again shift exclusion/inclusion criteria because COVID-19 cases have decreased in the Unites States recently.

As the authors note, further studies exploring best practices should focus on anticoagulation therapies, extremes of body habitus, filtration of cytokines, cannulation sites, timing of tracheostomy, bridge-to-transplantation, and the correlation of traditional scoring (Respiratory Extracorporeal Membrane Oxygenation Survival Prediction score) on 
both short- and long-term outcomes for COVID-ECMO..$^{4-7}$ Additionally, a comparison between patients treated conservatively (maximum medical therapy but not ECMO) is needed, but as other trials and studies have shown us repeatedly, hard to produce.

Rome was not built in a day, and neither will the knowledgebase for COVID-ECMO outcomes. Era-based studies tend to fall into 3 categories: what we know, what we now know, and what we thought we knew and each sequentially builds on the efforts of previous research. This article serves as a meaningful foundation for ECMO use in COVID-19 patients, and almost certainly, the need for reexamination with novel viral variations and future challenges.

\section{References}

1. Omar S, Tatooles A, Farooq M, Schwartz G, Pham D, Mustafa A, et al. Characteristics and outcomes of patients with COVID-19 supported by extracorporeal mem- brane oxygenation: a retrospective multicenter study. J Thorac Cardiovasc Surg. 2022;163:2107-16.e6.

2. Barbaro RP, MacLaren G, Boonstra PS, Iwashyna TJ, Slutsky AS, Fan E, et al. Extracorporeal membrane oxygenation support in COVID-19: an international cohort study of the Extracorporeal Life Support Organization registry. Lancet. 2020;396:1071-8.

3. Mitra S, Ling RR, Tan CS, Shekar K, MacLaren G, Ramanathan K. Concurrent use of renal replacement therapy during extracorporeal membrane oxygenation support: a systematic review and meta-analysis. J Clin Med Res. 2021;10:241.

4. Brodie D, Slutsky AS, Combes A. Extracorporeal life support for adults with respiratory failure and related indications: a review. JAMA. 2019;322:557-68.

5. Schmidt M, Bailey M, Sheldrake J, Hodgson C, Aubron C, Rycus PT, et al. Predicting survival after extracorporeal membrane oxygenation for severe acute respiratory failure. The respiratory extracorporeal membrane oxygenation survival prediction (RESP) score. Am J Respir Crit Care Med. 2014;189: 1374-82.

6. Kowalewski M, Fina D, Słomka A, Raffa GM, Martucci G, Lo Coco V, et al. COVID-19 and ECMO: the interplay between coagulation and inflammation-a narrative review. Crit Care. 2020;24:205.

7. Hartman ME, Hernandez RA, Patel K, Wagner TE, Trinh T, Lipke AB, et al. COVID-19 respiratory failure: targeting inflammation on VV-ECMO support. ASAIO J. 2020;66:603-6.
See Article page 2107.

\section{Commentary: Extracorporeal membrane oxygenation for Coronavirus Disease 2019: A step toward enlightenment or still flying blind?}

William C. Frankel, MD, James J. Yun, MD, PhD, and Aaron J. Weiss, MD

The environment in which we found ourselves during the first wave of the Coronavirus Disease 2019 (COVID-19) pandemic demanded rapid resource mobilization and a constantly adapting approach. In critically ill patients with

From the Department of Thoracic and Cardiovascular Surgery, Heart, Vascular and Thoracic Institute, Cleveland Clinic, Cleveland, Ohio.

Disclosures: The authors reported no conflicts of interest.

The Journal policy requires editors and reviewers to disclose conflicts of interest and to decline handling or reviewing manuscripts for which they may have a conflict of interest. The editors and reviewers of this article have no conflicts of interest.

Received for publication May 19, 2021; revisions received May 19, 2021; accepted for publication May 20, 2021; available ahead of print May 27, 2021.

Address for reprints: Aaron J. Weiss, MD, Department of Thoracic and Cardiovascular Surgery, Heart, Vascular and Thoracic Institute, Cleveland Clinic, 9500 Euclid Ave, Desk J4-1, Cleveland, OH 44195 (E-mail: weissa2@ccf.org).

J Thorac Cardiovasc Surg 2022;163:2118-9

$0022-5223 / \$ 36.00$

Copyright (c) 2021 by The American Association for Thoracic Surgery

https://doi.org/10.1016/j.jtcvs.2021.05.030

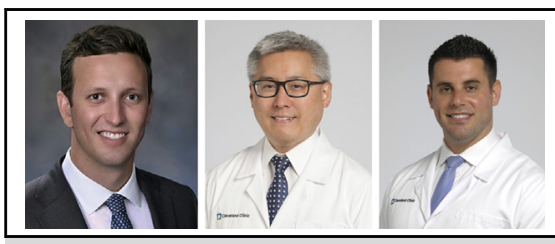

William C. Frankel, MD (left), James J. Yun, MD, PhD (center), and Aaron J. Weiss, MD (right)

CENTRAL MESSAGE

ECMO can be a viable therapeu-

tic option in the armamentarium

for patients with COVID-19

infection and acute respiratory

failure refractory to lung-

protective ventilator strategies.

acute respiratory failure refractory to lung-protective ventilator strategies, limited therapeutic options exist. At centers with the requisite resources, extracorporeal membrane oxygenation (ECMO) can be considered if appropriate and feasible. ECMO in patients with acute respiratory failure from other etiologies has been investigated previously ${ }^{1-3}$; however, there are limited data regarding its use in patients with COVID-19. 